\title{
NARRATIVAS E CORPOS
}

\section{NARRATIVES AND BODIES}

\section{SANTOS, Eduardo de Almeida (Eduardo Teffé)}

Mestre em Ciência da Literatura pela Universidade Federal do Rio de Janeiro - UFRJ .

Doutorando em Estudos de Literatura pela Universidade Federal do Rio de Janeiro - UERJ.

E-mail: eduardoteffe@gmail.com

ORCID ID: https://orcid.org/0000-0003-2368-8699

\section{MAGRI, Ieda Maria}

Doutora em Literatura Brasileira pela Universidade Federal do Rio de Janeiro - UFRJ

Professora adjunta do departamento de Literatura Brasileira e Teoria da Literatura da Universidade Estadual do Rio de Janeiro - UERJ.

E-mail: iedamagr@yahoo.com.br

ORCID ID: https://orcid.org/0000-0002-4809-38

\section{RESUMO}

Neste ensaio, pretendemos analisar as questões de atravessamento entre arte, território e disputa dos discursos e modelos de representação feitos por corpos e narrativas de sujeitos periféricos - muitas das vezes enquadrados como vidas precárias -, considerando como objeto de estudo específico os trabalhos e pensamentos de Taísa Machado e Sandro D' França. Assim, buscamos analisar as práticas desses artistas para pensar e tensionar as linhas força que atuam tanto sobre a escrita como na presença dos corpos em seus processos e nas articulações de suas vivências.

Palavras-chaves: Arte; narrativa; corpo.

\begin{abstract}
In this essay, we intend to analyze the issues of crossing between art, territory and dispute of discourses and representation models made by bodies and narratives of peripheral subjects - often framed as precarious lives - considering as a specific object of study the works and thoughts of Taísa Machado and Sandro D' França. Thus, we seek to analyze the practices of these artists to think and tension the lines of force that act both on writing and on the presence of bodies in their processes and in the articulations of their experiences.
\end{abstract}

Keywords: Art; Narrative; bodie. 


\section{APRESENTAÇÃo}

O Poder requer corpos tristes. O Poder necessita de tristeza porque consegue dominá-la. A alegria, portanto, é resistência porque ela não se rende. A Alegria como potência de vida nos leva a lugares onde a tristeza nunca levaria."

Gilles Deleuze.

De que forma a arte pode operar nas disputas de narrativas e pertencimento? Como o fazer artístico pode potencializar sujeitos que constantemente enfrentam a violência ilegítima do Estado, a fome e a pandemia? Daqueles que são considerados como parte de populações constantemente enquadradas como "destrutíveis" ou "não passíveis" de luto, ou ainda, consideradas populações perdíveis ou sacrificáveis como nos diz Judith Butler em Quadros de Guerra (2015). "Assim há 'sujeitos' que não são reconhecidos como sujeitos e há 'vidas' que dificilmente - ou melhor dizendo, nunca - são reconhecidas como vidas" (BUTLER, 2015, p.17).

Butler questiona em que circunstâncias é possível lamentar uma vida perdida? Quais são as vidas que são consideradas como não passíveis de luto? Que tipo de fatores levariam a essa percepção por parte da sociedade de que algumas vidas teriam direito ao choro e ao luto e que outras vidas poderiam ser consideradas como perdíveis, considerando a negação do direito de existência (e até a morte) como resultado da ações humanas, institucionais ou políticas. Se em nossa sociedade só reconhecermos a certas vidas o direito de aspirar a uma vida plena e protegida; se só nos enlutamos quando essas vidas desaparecem, Butler nos lança a pergunta de por que choramos por estas vidas e por outras não? Em um resumo, poderíamos dizer que a dor que sentimos por estas vidas perdidas implicaria na percepção de que elas deveriam ter tido a oportunidade de viver de forma plena, de desejar e estar em uma vida que não fosse de sofrimento contínuo e privação, mas uma vida vivível. Ao pensar sobre as vidas precárias e as vidas passíveis de luto, Butler diz que o reconhecimento dos sujeitos enquanto vidas que importam depende de certas condições, normas e categorias.

É sintomático registrar o momento de escrita deste ensaio: um estado aprofundado na desigualdade social que sofre em meio a uma pandemia. Além disso, as notícias recentes dão conta de desabamentos de casas populares e de uma chacina na favela do Jacarezinho. Estes acontecimentos são exemplos da violência que sofrem as populações consideradas marginalizadas, muitas vezes tomadas, pelo poder público, 
como não passíveis de luto, como vidas matáveis. É dentro deste contexto que existem trabalhos de artistas que desdobram o fazer artístico em militância de vida. Trabalhos que conectam e articulam práticas, registros, disputas e relações com a cidade e a sociedade. Nosso fio condutor será a questão: de que forma esses trabalhos transformam condicionantes considerados como carências em agenciamentos de potência? Buscaremos responder a esta questão analisando as ramificações e os pensamentos de Taísa Machado no Livro O Afrofunk e Ciência do Rebolado, da coleção Cabeças da Periferia (editora Cobogó-2020), bem como as ações e a dramaturgia de Sandro D 'França, principalmente sobre a web série Sexo: Outros - a desconstrução (produção Dalata filmes e Cia Última Estação2021).

\section{TAÍSA MACHADO: O corpo como empoderamento}

O meu trabalho, pra quem não sabe, fala que esses são saberes legítimos de mulheres pretas. E que eles podem estar em muitos lugares, no baile funk, no ritual, no twerk da Beyonce, mas são saberes. $E$ eles têm amplitude: batem na saúde, na espiritualidade, em como você é na sociedade, na cidadania, na coisa social, no ecossistema social.

Taísa Machado

No ano de 2020, a editora Cobogó lançou a coleção Cabeças da periferia estruturada na época pandêmica como um livro-entrevistaregistro feito com atuantes da cultura da periferia e tendo a organização de Marcus Faustini. Ele também conduziu os bate-papos, que contaram com a participação de convidados como Emilio Domingos, Sinara Rúbia e Isabel Diegues.

Os primeiros três livros da série apresentaram os trabalhos de três cariocas: o comunicador Rene Silva, fundador do jornal carioca "Voz das Comunidades", o escritor Jessé Andarilho, autor de Fie/ e Efetivo Variável, e a dançarina e pesquisadora Taísa Machado. As conversas giraram em torno de temas como cultura, ativismo, circulação na cidade e o processo de criação dos entrevistados, como constroem suas narrativas, suas relações com a cidade e o desenvolvimento do pensamento crítico. As artes das capas foram assinadas pelo artista visual carioca Maxwell Alexandre (que incorporou diversos elementos da cultura periférica). 
Em Afrofunk e a Ciência do Rebolado, somos apresentados a essa dançarina, professora e escritora, a chamada "Chefona"1, criadora do Afrofunk, uma oficina de dança concebida para descolonizar o corpo feminino. "Chefona" expõe, ao longo das páginas do livro, os princípios de sua Ciência do Rebolado, método desenvolvido a partir de técnicas para soltar os quadris, sobretudo graças a danças da diáspora negra, como funk, twerk e dance hall, entrelaçadas com danças tradicionais africanas e asiáticas, que exploram os movimentos da pelve. Através de diversas histórias, ela fala sobre suas investigações acerca do corpo feminino, da dança, do território, do universo dos bailes funk, dos trânsitos pela cidade, do teatro de rua e de sua descoberta do prazer com a escrita. Através da dança, Taísa provoca a consciência corporal, despertando corpos para que atinjam toda sua potência revolucionária.

O livro se constrói a partir de perguntas e reflexões sobre o trabalho e a história prática - além de pensamentos e narrações da trajetória. Sobre isto, cabe ressaltar a observação contida no livro sobre as estratégias de Taísa:

Uma típica artista carioca, assim como os garotos do passinho, que são extremamente práticos e vão criando estratégias e métodos a partir da necessidade, e não tem limites nessa criação. Acho que é a partir disso que surgem as inovações, essa busca constante pro que é novo, essa abertura pro que é diferente. Ao mesmo tempo essa procura não é no vazio, eles estão procurando algo pra utilidade cotidiana. (MACHADO, 2020, p.58)

Percebe-se que não é gratuita a nomeação de Ciência do Rebolado - considerando que o porquê filosófico do movimento vem junto com o movimento em si (mas também considerando que ele se constrói na prática). Em relação ao exemplo de fazer artístico, Taísa cita um episódio especifico: fala sobre uma dançarina no baile do complexo de Lins. Através de uma narração rica ela constrói o cenário no qual esta bela mulher está usando uma burka de funk. Ela menciona que essa mulher brilhava no palco e que, após um movimento conhecido como "Surra de bunda", os bandidos que estavam presentes e extremamente felizes começaram a dar tiro para o alto e por conta disso estilhaços começaram a cair na dançarina, mas para a surpresa e admiração de Taísa, essa mulher continuou dançando de forma magnética "fazendo o trabalho dela, com estilhaço de bala pegando nela, entendeu?" (MACHADO, 2020, p.18). Algo incrível até para ela que fazia teatro com o Amir Haddad no grupo Tá na Rua.

\footnotetext{
${ }^{1}$ Apelido pensado por ela após uma epifania em uma Gira de Umbanda. 
Ao longo do livro, somos apresentados a outras danças e músicas que surgem como resistência e que se desenvolvem em contextos opressores, como o jongo, jazz e a capoeira. A comparação desta resiliência ao ambiente opressor e sua potencialização da arte é observada no pensamento "o cara se desenvolve na guerra, na luta, é uma marca histórica do modo de fazer, de ser e estar, mesmo no momento mais difícil. Isso é resiliência que se transforma em arte." (ibid, 2020, p. 87).

Sobre a ciência do rebolado ele se debruça sobre os caminhos do corpo e movimentos em territórios de vulnerabilidade. Mas, cabe notar que a vida é potência e resiste como afirmação. E os caminhos podem ser percorridos em direções inversas. Podem-se usar as estratégias de dominação como ferramentas de libertação. A "verdade" é que as estratégias são só estratégias. Dominação ou libertação dependem do seu uso e do contexto.

Deleuze, por exemplo, dizia que é a repressão que determina a diferença entre os dispositivos (de controle) para os agenciamentos de desejo. Logo, um dos focos de Taísa é que as meninas da periferia possam perceber 0 poder que a dança tem: que as praticantes das oficinas adquiriram conhecimentos oriundos de uma oralidade, de uma corporalidade, assim como musicalidade e ancestralidades negras. E que esses conhecimentos possam ser reproduzidos e fisicalizados no corpo a partir da criação.

Essa expansão e reprodução podem ser percebidas além da dança em múltiplas linguagens: Instagram, internet, aula... Formas que Taísa considera ações de opinar e estar presente no mundo. Sobre isto cabe destacar a presença da Chefona na escrita

Eu sempre gostei de ler, mas não sabia o que ler. Hoje eu tenho mais referências, posso escolher o que ler. Antes eu lia o que tava na mão. Nunca tinha pensado "Ah, um dia eu posso escrever um livro". Nunca. Eu escrevia na internet e as pessoas curtiam, mas eu não tinha ideia da dimensão. (ibid, p.78)

Estas questões de poder pertencer são importantes. É importante pertencer e estar presente tanto corporalmente como em narrativas. É notório observar que o vivente possui a linguagem e que o estado de exceção traz à Zona de Indiferença, uma zona em que não percebemos o outro como uma vida importante e digna do vivível . O que acaba por gerar o sequestro do corpo para todo o ato além das convenções e produz a sensação ou a crença de não ser digno de se narrar. Essa indiferença sobre 
a narrativa pode ser explicada pelo racismo estrutural que atinge nossa sociedade.

No final das contas, é a velha questão do racismo. Eu não tinha nenhuma referência de alguém como eu que tinha escrito um livro. Não sabia que podia. Já achava que existia pouca mulher que escrevia. $E$ mais que isso, o jeito do Geovani escrever: as figuras, o formato das coisas, o universo social dos personagens, o tipo dos personagens, o tipo de escrita, de assunto, o jeito de lidar com a língua portuguesa, nada disso eu tinha visto antes. (ibid, 2020, p.79)

De certa forma as comunidades ditas marginalizadas foram incluídas economicamente por estratégias de governos anteriores, mas essa inclusão não incluiria tudo de fato. De certa forma, como Badieu nos fala de forma análoga sobre representar sem apresentar: "define normal um termo que está, ao mesmo tempo, apresentado e representado (isto é, pertence e está incluído), excrescência um termo que está representado, mas não apresentado (que pertence sem estar incluído)" (998, p.95-115, apud AGAMBEN, 2002, p.31). Logo muitas das vezes estas ioulaç eos estão colocados em estado de excrescência onde se pertence mas não se está incluido.

Ainda no livro de Agamben é possível evocar para esta análise do sentido das possibilidades de vida, através da definição Aristotélica da polis e da oposição entre viver (zên) e viver bem (eû zên), ou seja, a diferença entre a vida nua e a vida qualificada para que assim possamos perguntar: como aqueles incluídos pela exclusão podem de fato estar presentes em vidas qualificadas? Se concordarmos que toda pessoa deveria ser livre, ter direito ao viver bem, então acreditamos que toda vida deveria pertencer a uma vida qualificada. Uma das questões do viver bem é o direito ao pertencimento e por consequência ter direito a sua narração e sua história, como nos diz Taísa: "É preciso se narrar, porque assim é que as pessoas ficam vivas [...]. Sou de uma cultura que acredita na história narrada, então, preciso contar a minha história, pra contar as de outras pessoas. É assim que a coisa toda funciona" (MACHADO, 2020, p.11). Este direito ao narrar ou não, seria uma das respostas possíveis a Butler (2015) dentro de suas indagações de: em que circunstâncias é possível lamentar uma vida perdida? De quem são as vidas consideradas choráveis em nosso mundo público? Quais são essas vidas que, se perdidas, não são percebidas como perda? 


\section{SANDRO D'FRANÇA: Palavra, disputa e pertencimento}

Eu creio no poder das palavras, na força das palavras, creio que fazemos coisas com as palavras e, também, que as palavras fazem coisas conosco. As palavras determinam nosso pensamento porque não pensamos com pensamentos, mas com palavras, não pensamos a partir de uma suposta genialidade ou inteligência, mas a partir de nossas palavras. E pensar não é somente "raciocinar" ou "calcular" ou "argumentar", como nos tem sido ensinado algumas vezes, mas é sobretudo dar sentido ao que somos e ao que nos acontece. $\mathrm{E}$ isto, o sentido ou o sem-sentido, é algo que tem a ver com as palavras. $E$, portanto, também tem a ver com as palavras o modo como nos colocamos diante de nós mesmos, diante dos outros e diante do mundo em que vivemos. $\mathrm{E}$ o modo como agimos em relação a tudo isso. (LARROSA, 2001, p. 21)

Segundo Sandro D `França, a Cia Teatral Última Estação surgiu da necessidade dos atores locais contarem suas próprias histórias, já que elas também são universais. O grupo tem uma estética teatral desenvolvida a partir da ação de ir para as ruas e casas do seu território, onde inicialmente recolhiam, por meio de entrevistas com papel e caneta ${ }^{2}$, boas histórias de moradores, para transformar estas em "dramaturgia nos palcos" (expressão usada pelo dramaturgo). Ou como diria Jesse Andarilho em outro livro da editora Cobogó:

Por que eu vou valorizar mais Paris do que Antares, do que Paciência, do que Cesarão? Por que eu contar a história de Copacabana e Ipanema, se eu posso contar de Antares? Eu escrevo com a intenção de mostrar que o lugar onde você mora tem a mesma importância que os outros, também faz parte do planeta. (ANDARILHO, 2020, p.19)

Há quase 20 anos $^{3}$, a companhia desenvolve um trabalho de pesquisa teatral nas periferias do Rio de Janeiro, mais precisamente no bairro de Santa Cruz, com a intenção de criar suas histórias e espetáculos. O grupo nasceu em 2008, com alunos recém-formados da Escola Livre de Teatro (ELT) do Projeto Reperiferia, que se instalava na Cidade das

\footnotetext{
${ }^{2}$ Hoje este material foi substituído em grande parte por smartphones.

${ }^{3}$ Considerando que o trabalho não é ininterrupto pois os artistas muitas das vezes tem que se dedicar a outras tarefas economicas se distanciando da possibilidade de práticar arte de forma integral.
} 
Crianças, também em Santa Cruz. O próprio nome faz alusão ao fato de Santa Cruz ser a última estação do ramal de trem. Desde então, houve diversos espetáculos, contando histórias reais de moradores da periferia. A companhia já apresentou os seguintes esquetes: "9 Filhos", "A Horta de Hortega", "Do outro lado da Serra", "Uma Dúzia de Trabalhos", "Nós, os Cantores do Rádio", "Medeias XXIII". Já em relação às peças o grupo, apresentou e montou através de editais públicos, as peças "Guandu - o caminho de um rio" e o infantil "Oh! Menino". Além disto, o grupo desenvolveu oficinas de teatro e formação para fornecer atores para as montagens e fazerem adaptações de outros textos para o Universo de Santa Cruz.

O novo projeto, Sexo a descontrução, acompanha Izabella Tiezzi, mulher trans, negra, candomblecista e moradora de um bairro periférico. Sandro conheceu ela pessoalmente antes da transição, como frequentadora de uma de suas oficinas. Antes do inicio da pandemia o projeto era a "tradicional" adaptação da história para os palcos. Porém, com a pandemia o projeto foi adaptado para algumas etapas diferentes: a realização de uma web série (durante a pandemia), estreia de peça para o pós-pandemia e episódio especial e documental para mostrar os resultados e depoimentos pós-peça. É importante observar as diversas ocupações de espaços e formatos das apresentações do projeto, espelhando e indo além de o "OH Menino", que se apresentou em teatros importantes do Rio de Janeiro, mas também na rua do personagem principal no Conjunto do João XXIII, fazendo a narração de si não apenas com o território, mas também no território.

Sobre o primeiro episódio da web série nós acompanhamos a abertura com a personagem se montando e em seguida ela, caminhando em um lugar ermo e rural (provavelmente uma rua do conjunto João XXIII que liga a empresa Ternium) e, logo em seguida, ouvimos o monólogo interior da personagem que começa com as seguintes palavras "agora minhas lágrimas vão virar falas e quem sabe com isso, pesem menos" depois uma caminhada por uma rua, um campo agrícola, depois a imagem de uma pessoa que é agredida e ainda sim tem uma continuação do caminhar. É importante notar os dois gestos de presença: o do corpo que atravessa o espaço e das palavras que costumeiramente não são ouvidas. Para finalizar essa cena, a personagem coloca os fones no ouvido (segundo Sandro D 'França, para evitar ouvir os xingamentos e as "gracinhas" na rua).

Em seguida, somos transportados para o passado do personagem em uma entrevista na qual demorou em preencher a ficha de emprego. É discriminado na entrevista de emprego, em uma fala "Além de preto, ainda 
é viado"4 que o personagem ouve após voltar para pegar uma chave esquecida.

$\mathrm{Na}$ próxima cena somos apresentados a uma personagem, que conversa com Izabella para tentar consola-la em relação ao episódio de preconceito. Além da interação com a personagem principal, esta personagem enfrenta o assédio moral do namorado ao se distanciar na cena ouvindo uma violência verbal. Lembrando outras formas de opressão que sofrem as mulheres (mesmo as que não terão sua história narrada na web série). Logo em seguida, ao chegar em casa, a personagem Izabella, que enfrenta uma crise, após não conseguir trabalho ouve sobre as dificuldades financeiras da familia, que estava tudo caro e que contavam com ela para conseguir um emprego.

Esses problemas ficam em segundo plano. Após uma fala direta de Isabella à mãe na qual vemos o passado da genitora alguns problemas aparecem: pobreza, um pai violento que preferia um menino, envolvimento deste com drogas entre outras coisas. Ao final do episódio, podemos ver em uma cena pós crédito, uma fala direcionada ao público por Sandro D' França - marcando que não é só ficção, mas também algo documental. Nesta fala alguns dados são apresentados como Isabel ${ }^{5}$ ter sido sua aluna e a explicação que o título é uma alusão a dificuldade que a personagem tinha ao preencher o perfil para vagas de empregos (homem, mulher, outros) e na dificuldade de se identificar como uma mulher trans.

Sobre a questão da identidade e diferença, podemos observar em Mbembe (2018), que o pensamento europeu engendrou a noção de identidade de forma hierárquica e como diferença, e todos aqueles que não eram europeus (superiores) foram considerados como "outro" (inferiores). Podemos considerar que este tipo de hierarquização pode gerar a figura de inimigo ou do não significante. E que esta se dá de forma situada e depende de certas condições de determinado tempo/espaço, por isso, a ideia do inimigo é sempre maleável, plástica - sujeitas a condicionantes históricos e sociais. Estes inimigos podem sofrer a violência e não serem enlutáveis. Cabe ainda notar que a violência não é apenas um ato isolado mas também uma atmosfera, uma condicionante de possibilidades em que ela pode ser exercida. Ou vetorizada através de estratégias de invisibilidade e não pertencimento.

Sobre Sandro D `França, uma outra informação de destaque é que ele é um morador nascido e criado no bairro de Santa Cruz e que tem sua

\footnotetext{
${ }^{4}$ As discriminações na sociedade do rio de janeiro acontecem em função de cor, sexo, condição econômica, região geográfica etc...

${ }^{5}$ Nome real da pessoa que inspirou a série.
} 
dramaturgia voltada para acontecimentos cênicos práticos ${ }^{6}$. Suas histórias tentam dar visibilidades a pessoas e comunidades que costumeiramente não tem suas histórias vistas. De certa forma, é a observação do mundo ordinário como matéria prima do acontecimento artístico, como esclarece Spolin (2010, p. 13), quando afirma que "o mundo fornece o material para o teatro e o crescimento artístico desenvolve-se par e passo com nosso reconhecimento percepção do mundo e de nós mesmos dentro dele".

Nesse sentido, D'França não escreve uma "dramaturgia de gaveta". Ao menos por enquanto, não cria peças e/ou esquetes para serem encenadas posteriormente por algum outro coletivo. Seu desenvolvimento da escrita e encenação é próximo, quase que simultâneo. É o processo de colher histórias e ir moldando-as através de exercícios, improvisos e jogos junto ao coletivo. Uma espécie de dramaturgia coletiva, orientada e proposta por um dramaturgo (parecida com as proposições do dramaturgista português Jorge Silva Melo $^{7}$ ). Nesta empreitada ele também conta com a equipe do Dalata filmes, um empreendimento fílmico social que merecia um artigo próprio.

Outro ponto é que Sandro fundou o coletivo junto a um grupo de amigos a partir de uma história que Ihe interessava e a encenou através das possibilidades de material humano que dispunha entre colegas na Lona Cultural Sandra de Sá e na ELT ${ }^{8}$. Como nos diz Boal:

Teatro é a capacidade dos seres humanos de se observarem a si mesmo em ação. Os humanos são capazes de se ver no ato de ver, capazes de pensar em suas emoções e de se emocionar com seus pensamentos. Podem se ver aqui e imaginar adiante, podem se ver como são agora e se imaginar como serão amanhã. (BOAL, 2011, p.14)

É uma escrita arqueologia de reconexão do ser com o ente no qual as histórias dos sujeitos e territórios sejam encenados e feitos para os mesmos. Tentando viabilizar através de agênciamento dramaturgicos, a visibilidade e o direito ao pertencimento. Óbvio que para que isto se

\footnotetext{
${ }^{6}$ É uma dramaturgia que se molda no fazer e nas relações com o público que só acontece no contato do processo do dramaturgo, com o mote coletado e a criação dos atores.

7 Importante Dramaturgo português autor de obras como "Antonio um rapaz de Lisboa" que trabalha com uma dramaturgia de "Cozer" no qual vai criando a escrita cênica a partir de acontecimentos e vivências experimentados nos ensaios e procedimentos cênicos.

${ }^{8}$ A relação com a ELT é interessante, pois a mesma foi uma escola de interpretação cênica pouco focada em aspectos teóricos e principalmente em estruturas dramáticas textuais. Este fato será notado na carência de aspectos formais e "técnicos" (no sentido do padrão) observados no texto bruto, que não apresenta uma "formatação correta".
} 
concretize de forma plena é necessário o ganho para além do capital simbólico: os ganhos de capitais e de politicas sociais.

Marina Henrique Coutinho (2012, p. 22) faz a seguinte pergunta:

Quais circunstâncias favorecem a comunidade-favela para exercer o seu papel como autora dos processos criativos ou a sua autonomia dentro de um "projeto"?; que tipo de política estabelecida entre "agentes externos" e comunidades é capaz de criar uma relação que garanta à comunidade o seu verdadeiro direito de voz?; ou, ainda, que circunstâncias permitem que os projetos respirem dentro da dinâmica da comunidade-sujeito, assegurando à favela/comunidade o seu direito de, por meio do teatro, nomear o mundo?

A literatura de periferia no Brasil tem extrema ligação não só com a questão de dar voz, como por apresentar a voz dos sujeitos excluídos das tradicionais formas de representação e, muitas vezes, tendo a arte como propósito, como nos diz Andarilho:

Eu penso nisso porque, quando to escrevendo, não escrevo por escrever. As minhas histórias são intencionais. Gosto de mostrar as dificuldades, tanto dos meus personagens quanto do autor. O Fiel acontece em Antares, o Efetivo variável acontece em Santa Cruz, mas o morador é de Antares. O próximo livro que eu to escrevendo agora, que vai sair pela Companhia das Letras que é O Esquema [livro no prelo], o morador é de Paciência. A batalha, que eu tô escrevendo, sobre batalha de rima, o personagem é de Campo Grande. Eu quero daqui a 300 anos a pessoa que for investigar o Rio de Janeiro diga: Pô, antigamente tinha um autor que escrevia sobre a Zona Oeste do Rio de Janeiro, cada livro dele fala de um bairro e tal. Eu penso lá na frente, Faustini, penso daqui a 300 anos. Tudo que eu faço, qualquer palavra que eu escrevo, tanto no Facebook quanto no Twitter ou no instagram, tem um interesse. Não escrevo por escrever. Tem uma mensagem, e aquela questão da representatividade. Não só pela cor, pela origem, mas pelo bairro também. A gente fala que tem que ganhar o mundo, né? Mas a gente tem que fincar a raiz. Tem que ter a raiz. Tem que ter a raiz, mas também tem que voar. A minha forma de plantar minha raiz e voar é essa. (ANDARILHO, 2020, p.18) 
É neste sentido que existe o pertencimento das metodologias da Taísa e das narrativas como propósito. É a transformação da percepção do sujeito, da vida e do território através destas ações artísticas. Sejam em oficinas, falas ou objetos artísticos.

\section{CONSIDERAÇÕES FINAIS}

As situações de opressões vividas em perfierias urbanas como o Rio de Janeiro não se dão apenas por questões financeiras, mas também por aspectos simbolicos (ou pela inexistencia deles). Assim o espectro da violência e do não enlutavél se dão baseados em um clima de não valorização da vida e da negação de narrativas e visibilidades. Tornando estas populações como estranhas e não pertencentes. É possivel ainda observar um aprofundamento disto de acordo com gênero, sexo, raça, território e posição econômica. Por isto estas ações artística tem tanta importância. Pois stas operações artísticas de narração e dança são possibilidades de construção-invenção da realidade e da afirmação da possibilidade da diferença.

É possível dizer que estas práticas artísticas não se enquadram apenas como arte. Mas fazem o atravessamento das fronteiras levantadas sobre representação e vida. Trabalhando na construção e invenção de novos espaços-tempos bem como na visibilidade de subjetividades perifericas, é possível pensar a arte como ferramenta de mudança e para a visibilidade da realidade, seja com discursos ou práticas corporais ou com a abertura da possibilidade de recriar a forma de se relacionar com a cidade e a vida. Esse tipo de gesto, traz a presença da palavra na vida como vetor possível de existência e resistência, pois produzem agenciamentos que tentam dar visibilidade a narrativas e vivências para tentar superar algumas das condições que geram o pensamento de que algumas vidas são consideradas como não enlutáveis. Através de narrativas de pertecimento, de ações práticas nos territórios, de atividades que disputam o espaço das relações objetivadas entre indivíduos e coletividades é possível buscar o fortalecimento da democracia, a superação das desigualdades e o reconhecimento e a legitimação das diferenças. 


\section{REFERÊNCIAS}

ANDARILHO, Jessé. Jessé Andarilho, a escrita, a cultura e o território/ Jessé Andarilho; organização Marcus Faustini ; comentadores Julio Ludemir, Rossi Alvis, Isabel Diegues. 1. Ed. Rio de Janeiro: Cobogó, 2020.

AGAMBEN, Giorgio. Homo Sacer: 0 poder soberano e a vida nua I / Giorgio Agambenj traduçao de Henrique Burigo. - Bela Horizonte: Editora UFMG, 2002.

BOURDIEU, P. As regras da arte. Gênese e estrutura do campo literário. Trad. de Maria Lúcia Oliveira. São Paulo: Cia. das Letras, 1996.

BUTLER, Judith. Quadros de Guerras. Quando a vida é passível de Luto. Judith Butler. Tradução Sergio Tadeu de Niemeyer Lamarão e Arnaldo Marques da cunha; revisão de tradução de Marina Vargas; revisão técnica de Carla Rodrigues. 1. ed.- Rio de Janeiro: Civilização Brasileira,2015.

COUTINHO, Marina Henriques. A Favela como Palco e Personagem. Petrópolis/ RJ. 2012.

Teatro e dança como Experiência comunitária. Organização: Narcisio Telles; Victor Hugo Pereira; Zeca Ligiéro. Nós do Morro - teatro e educação na formação de crianças e jovens do Vidigal: uma experiência que se multiplica. Rio de Janeiro: EDUERJ,2009. P.109124

LARROSA, Jorge. Notas sobre a experiência e o saber de experiência. Palestra proferida no $1^{\circ}$. COLE -Congresso de Leitura do Brasil. Unicamp, Campinas - SP, 2001.

MARQUES, Isabel A. Ensino de Dança hoje textos e contextos. São Paulo: Cortez, 2017.

MBEMBE, A. Crítica da Razão Negra. São Paulo, SP: n-1edições. 2018.

RYNGAERT, Jean-Pierre. Ler o teatro contemporâneo. SP: Martins Fontes, 1998.

SANTOS. Eduardo de Almeida (Eduardo Teffé). A NARRATIVA COMO DISPOSITIVO: a interferência da palavra na disputa da existência em certos territórios do Rio de Janeiro. 2015. 125 páginas. Ciência da Literatura. UFRJ., Rio de Janeiro. 


\section{OUTRAS REFERÊNCIAS}

Entrevista com Sandro D' França https://youtu.be/TTPFC9L8szA (Acessado em 18/05/2021).

Episódio 1 sexo: a descontrução https://www.youtube.com/watch?v= mtktODmVcBU\&t=41s

Recebido em: 16/06/2021

Aceite em: 04/12/2021 